Article

\title{
Substituent Effects on the Crystal Structures of Salts Prepared from (R)-2-Methoxy-2-(1-naphthyl)- propanoic Acid and $(R)-1$-Arylethylamines
}

\author{
Akio Ichikawa ${ }^{1, *}$, Hiroshi Ono ${ }^{2}$ and Yuji Mikata ${ }^{3}$ \\ 1 Institute of Agrobiological Sciences, National Agriculture and Food Research Organization (NARO), \\ Tsukuba 305-8634, Japan \\ 2 Advanced Analysis Center, National Agriculture and Food Research Organization (NARO), \\ Tsukuba 305-8642, Japan; ono@affrc.go.jp \\ 3 Department of Chemistry, Biology, and Environmental Science, Faculty of Science, \\ Nara Women's University, Nara 630-8506, Japan; mikata@cc.nara-wu.ac.jp \\ * Correspondence: a.ichikawa@affrc.go.jp; Tel.: +81-29-838-6267 \\ Academic Editor: Dmitriy V Soldatov
}

Received: 26 July 2017; Accepted: 22 August 2017; Published: 28 August 2017

\begin{abstract}
The crystal structures of salts 6-9 prepared from (R)-2-methoxy-2-(1-naphthyl)propanoic acid $[(R)-\mathrm{M} \alpha \mathrm{NP}$ acid, $(R)-1]$ and (R)-1-arylethylamines [salt 6, (R)-1-(4-methoxyphenyl) ethylamine.(R)-1; salt 7, $(R)-1$-(4-fluorophenyl)ethylamine.(R)-1; salt 8, $(R)-1$-(4-chlorophenyl) ethylamine.(R)-1; and salt 9, $(R)-1$-(3-chlorophenyl)ethylamine $(R)-1$ ] were elucidated by X-ray crystallography. The solid-state associations and conformations of the M $\alpha \mathrm{NP}$ salts were defined using the concepts of supramolecular- and planar chirality, respectively, and the crystal structures of salts 6-9 were interpreted as a three-step hierarchical assembly. The para-substituents of the $(R)-1$-arylethylammonium cations were found on sheet structures consisting of $2_{1}$ columns. Thus, salts possessing smaller para-substituents, that is, salt $7(p-\mathrm{F})$ and salt $9(p-\mathrm{H})$, and larger para-substituents, that is, salt 6 ( $p$-OMe) and salt $8(p-\mathrm{Cl})$, crystallized in the space groups $P 2_{1}$ and $\mathrm{C} 2$, respectively. Additionally, weak intermolecular interactions, that is, aromatic $\mathrm{C}-\mathrm{H} \cdots \pi, \mathrm{C}-\mathrm{H} \cdots \mathrm{F}$, and $\mathrm{C}-\mathrm{H} \cdots \mathrm{O}$ interactions, were examined in crystalline salts $\mathbf{6 - 9}$.
\end{abstract}

Keywords: chiral recognition; crystal engineering; planar chirality; supramolecular chirality

\section{Introduction}

Stereochemistry is important in biofunctional molecules [1]. Therefore, methods that facilitate the elucidation of absolute configurations and the preparation of single enantiomers are highly desired [2]. Based on stereochemical studies of biofunctional molecules, we synthesized a chiral resolving agent, M $\alpha \mathrm{NP}$ acid (acid 1, Figure 1) [3,4]. Acid 1 is superior to Mosher's 3,3,3-trifluoro-2-methoxy-2-phenylpropanoic acid (MTPA, 2) [5] for the enantioresolution of secondary alcohols [2].

Goto et al. reported the enantioresolution of rac-1 via diastereomeric salt formation with $(R)-3$ [3]. In 2011, we examined the crystal structures of the less-soluble salt $4[(R)-3 \cdot(R)-1]$ and the more-soluble diastereomeric salt (R)-3.(S)-1 by X-ray crystallography [6]. Those crystal structures revealed a chiral recognition mechanism during the enantioresolution process. With the less-soluble salt 4 , the $(R)-\mathrm{M} \alpha \mathrm{NP}$ anion and the (R)-PEA cation form a close ion-pair via a methoxy-group-assisted salt bridge and aromatic $\mathrm{C}-\mathrm{H} \cdots \pi$ interactions (Figure 2A). The close ion-pairs then join with the salt bridges to form $2{ }_{1}$ columns. Additionally, results have shown that intercolumnar aromatic $\mathrm{C}-\mathrm{H} \cdots \pi$ interactions [7-9] are more effective with the less-soluble salt 4 . 
Recently, we introduced the concept of supramolecular chirality as a means of defining the association of close ion-pairs in the solid state [10]. Considering the virtual chiral center of the carboxylate and methoxy groups of the (R)-M $\alpha \mathrm{NP}$ anion and the phenyl and ammonium groups of the (R)-PEA cation, the supramolecular chirality of salt 4 was assigned as sup $S$ (Figure 2B) [10].

Salts 4 and $5\left[(R)-1-(p\right.$-tolyl)ethylamine. $(R)-1]$ yielded space groups $P 2_{1}$ and $C 2$, respectively $[6,11]$. This implied an effect of para-substitution of the PEA cation on the latter stage of hierarchical assembly $[12,13]$.

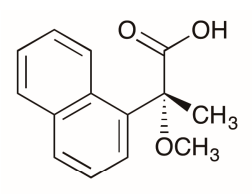

(R)-1: (R)-MaNP acid

(R)-MaNP- .<smiles>C[C@@H]([NH3+])c1ccccc1</smiles>

4

(R)-M $\alpha \mathrm{NP}^{-}$.

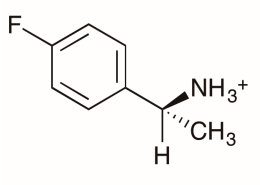

7

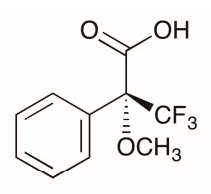

(R)-2: (R)-MTPA

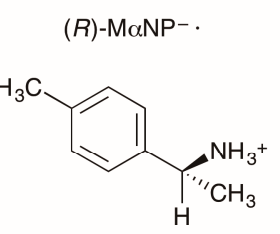

5

(R)-M $\alpha \mathrm{NP}^{-}$.

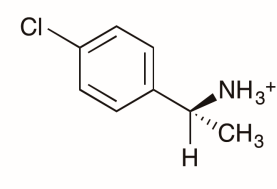

8<smiles>C[C@H](N)c1ccccc1</smiles>

(R)-3: $(R)$-PEA<smiles>COc1ccc([C@@H](C)[NH3+])cc1</smiles>

6

(R)-M $\alpha \mathrm{NP}^{-}$.

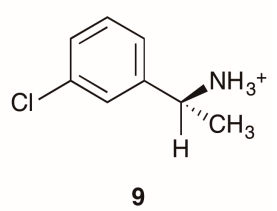

Figure 1. Structures of chiral resolving agents and $M \alpha N P$ salts. See refs. [6] and [11] for salt 4 (CCDC 801461) and salt 5 (CCDC 871216), respectively. (R)-M $\alpha \mathrm{NP}^{-}$represents the (R)-2-methoxy-2(1-naphthyl)propanoate anion.

(A)

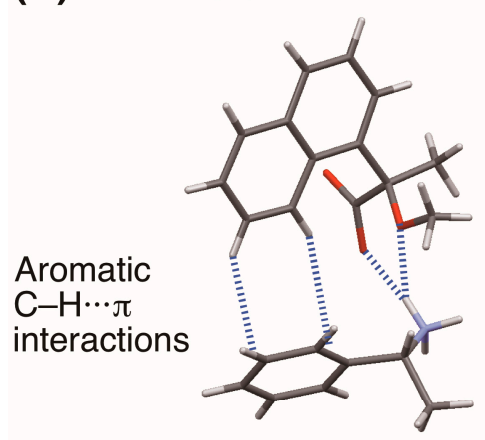

(R)-PEA cation
(B)

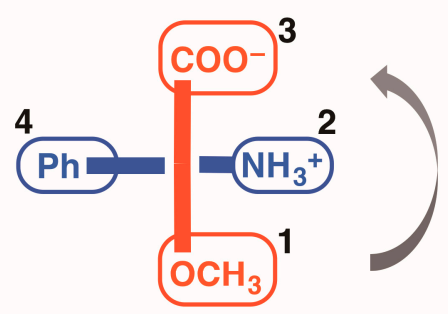

Supramolecular chirality: ${ }^{\text {sup } S}$

Figure 2. (A) Chiral recognition and (B) supramolecular chirality in the close ion-pair of the less soluble M $\alpha$ NP salt $4[6,10]$. Assigned numbers indicate priority based on the Cahn-Ingold-Prelog rules. The symbol "sup $S$ ” represents the left-handed supramolecular chirality. 
This report describes substituent effects on the crystal structures of salts 6-9. The 4-methoxyphenyland 3-chlrorophenyl groups were fixed in the crystal lattice. Thus, the planar chirality [14] of the (R)-1-arylethylammonium cations was assigned in salts $\mathbf{6}$ and $\mathbf{9}$. The molecular packing of salts 6-9 was interpreted as the three-step hierarchical assembly [12,13].

A large number of agrochemicals and pharmaceuticals are halogenated compounds. In 2007, Müller et al. reported that ca. $20 \%$ of all pharmaceuticals, and even more agrochemicals (up to $30 \%)$, contained fluorine atoms [15]. The ratio of chlorinated drugs was next to the fluorinated drugs in all halogenated drugs [16]. However, the effects of halogen atoms, especially fluorine, are ambivalent. Organic crystals are now considered a type of supermolecule [7]. Therefore, the elucidation of substitution effects in organic crystals will contribute to an overall understanding of weak intermolecular interactions. The current study explores aromatic $\mathrm{C}-\mathrm{H} \cdots \pi, \mathrm{C}-\mathrm{H} \cdots \mathrm{F}$, and $\mathrm{C}-\mathrm{H} \cdots \mathrm{O}$ interactions in crystalline salts $\mathbf{6 - 9}$.

Crystal engineering of organic salts is important as a means of enantioresolution [17-19]. Investigations of crystal structures provide information on weak intermolecular interactions that are useful in the design of biofunctional molecules.

\section{Results and Discussion}

\subsection{Preparation of Crystalline $M \alpha N P$ Salts}

Single crystals of salts 6-9 were prepared from (R)-1 and (R)-1-arylethylamines with $\mathrm{MeOH} / \mathrm{CHCl}_{3}$ and were analyzed using X-ray crystallography (Figure 1). Table 1 and Figure 3 show their crystallographic data and ORTEP diagrams, respectively. Salts 6 and $\mathbf{8}$ crystallized in the monoclinic space group $C 2$ with four ion-pairs per unit cell, while salts 7 and 9 belonged to the space group $P 2_{1}$ with two ion-pairs per unit cell. For salts possessing larger substituents, that is, salt 6 ( $p$-OMe), salt $8(p-\mathrm{Cl})$, and salt $\mathbf{9}(m-\mathrm{Cl})$, methanol molecules functioned as space-fillers [19], stabilizing the crystal lattice.

Table 1. X-ray crystallographic data for salts 6-9.

\begin{tabular}{ccccc}
\hline Compound & $\mathbf{6}^{\mathbf{1}}$ & $\mathbf{7}$ & $\mathbf{8}^{\mathbf{1}}$ & $\mathbf{9}^{\mathbf{1}}$ \\
\hline Molecular formula & $\mathrm{C}_{23.5} \mathrm{H}_{29} \mathrm{NO}_{4.5}$ & $\mathrm{C}_{22} \mathrm{H}_{24} \mathrm{FNO}_{3}$ & $\mathrm{C}_{22.5} \mathrm{H}_{26} \mathrm{ClNO}_{3.5}$ & $\mathrm{C}_{23} \mathrm{H}_{28} \mathrm{ClNO}_{4}$ \\
Formula weight & 397.49 & 369.43 & 401.91 & 417.93 \\
Crystal system & monoclinic & monoclinic & monoclinic & monoclinic \\
Space group & $\mathrm{C} 2$ & $P 2_{1}$ & $\mathrm{C}$ & $2_{1}$ \\
$Z$ & 4 & 2 & 4 & 2 \\
$a / \AA$ & $24.026(8)$ & $11.8064(12)$ & $28.612(5)$ & $11.5676(10)$ \\
$b / \AA$ & $6.790(2)$ & $6.7248(6)$ & $6.8078(9)$ & $6.8976(6)$ \\
$c / \AA$ & $14.800(5)$ & $12.7444(11)$ & $14.856(3)$ & $14.2838(14)$ \\
$\beta / /^{\circ}$ & $117.208(4)$ & $102.717(4)$ & $132.9310(16)$ & $109.467(3)$ \\
$V / \AA^{3}$ & $2147.3(12)$ & $987.03(16)$ & $2118.7(6)$ & $1074.54(17)$ \\
$D_{\text {calculated }} / \mathrm{g} \cdot \mathrm{cm}^{-3}$ & 1.229 & 1.243 & 1.260 & 1.292 \\
$\mu /$ mm & 0.084 & 0.088 & 0.205 & 0.206 \\
$2 \theta_{\text {max }} /^{\circ}$ & 54.9 & 54.9 & 54.9 & 54.9 \\
Temperature $/ \mathrm{K}$ & 123 & 123 & 123 & 153 \\
No. of reflections collected & 8451 & 7757 & 8312 & 10,547 \\
No. of reflections unique & 4857 & 4409 & 4671 & 4876 \\
$R_{\text {int }}$ & 0.0292 & 0.0190 & 0.0134 & 0.0115 \\
No. of parameters & 272 & 248 & 262 & 268 \\
Final $\left.R_{1}(I>2(\sigma) I)\right)^{2}$ & 0.0611 & 0.0402 & 0.0521 & 0.0336 \\
$w R_{2}$ (all data) ${ }^{3}$ & 0.1620 & 0.0984 & 0.1370 & 0.0963 \\
GOF & 1.127 & 1.077 & 1.036 & 1.061 \\
Flack parameter $^{4}$ & $1.7(15)$ & $1.1(7)$ & $-0.03(9)$ & $-0.02(4)$ \\
CCDC & $1,442,523$ & $1,442,524$ & $1,442,525$ & $1,442,526$ \\
\hline
\end{tabular}

${ }^{1}$ Crystals of salts $\mathbf{6}, \mathbf{8}$, and 9 were methanol solvates. ${ }^{2} R_{1}=\left(\Sigma|| F_{\mathrm{o}}|-| F_{\mathrm{c}}||\right) /\left(\Sigma\left|F_{\mathrm{o}}\right|\right) .{ }^{3} w R_{2}=\left\{\left[\Sigma w\left(F_{\mathrm{o}}{ }^{2}-\right.\right.\right.$ $\left.\left.\left.F_{\mathrm{c}}{ }^{2}\right)^{2}\right] /\left[\Sigma w\left(F_{\mathrm{o}}{ }^{2}\right)^{2}\right]\right\}^{1 / 2} .{ }^{4}$ The Flack parameters for salts 6 and 7 have no physical meaning because the salts do not contain heavy atoms. 


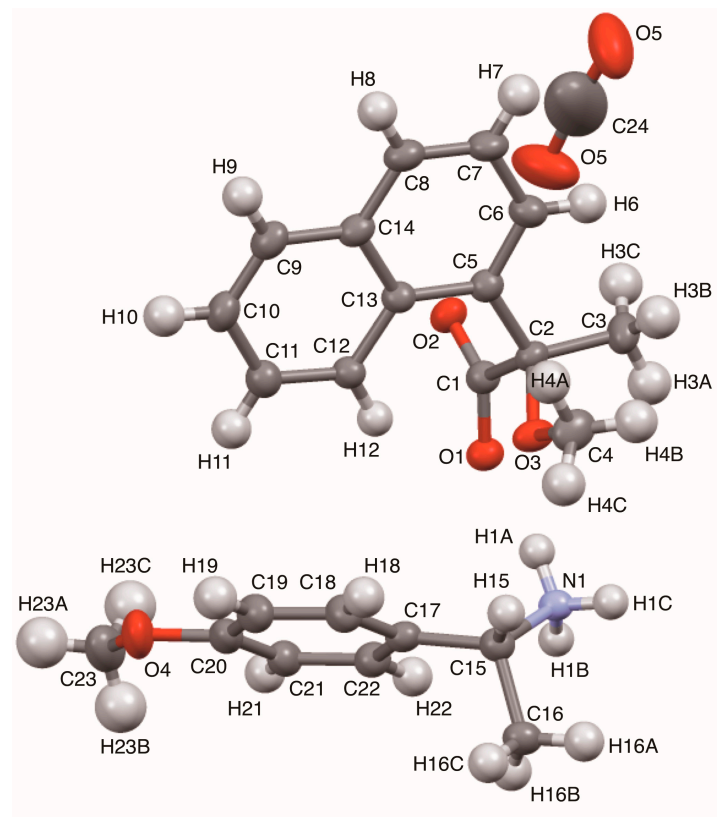

6
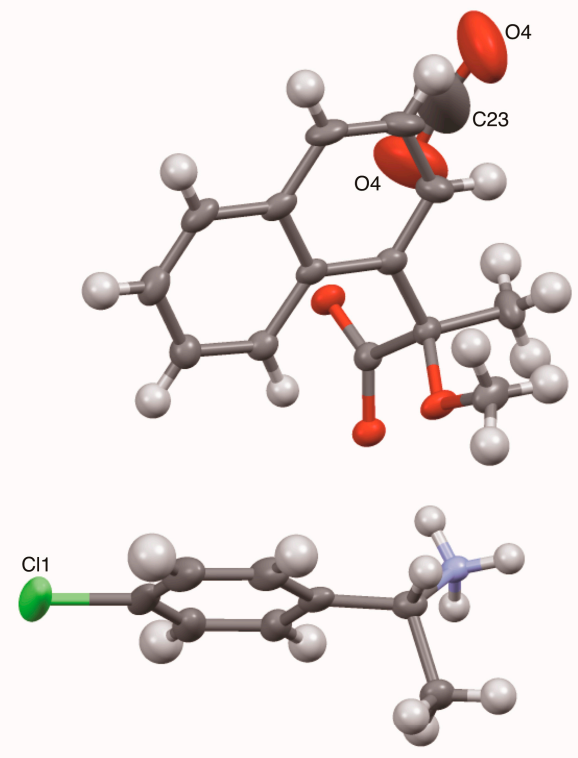

8
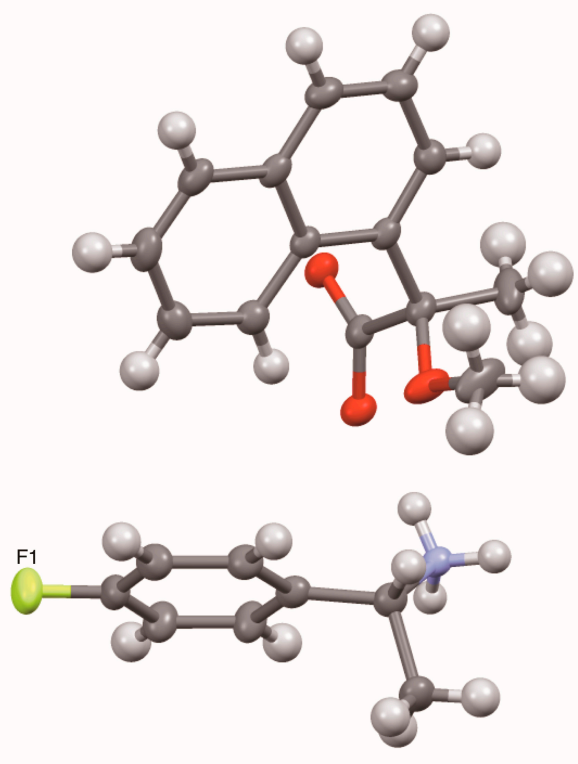

7
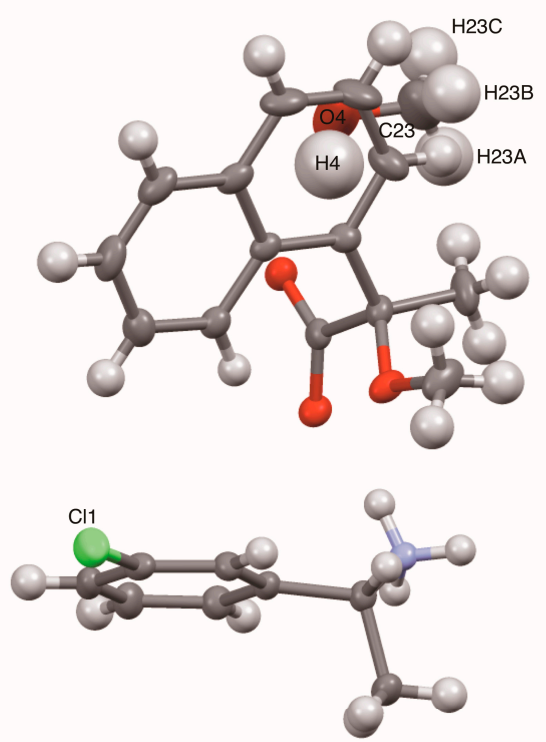

9

Figure 3. ORTEP diagrams of salts 6-9 with ellipsoids set at 50\% probability. Crystals of salts 6, 8, and 9 were methanol solvates. The methanol molecules in salts $\mathbf{6}$ and $\mathbf{8}$ showed positional disorder. The atom labels for salt 6 were also used for the other salts except for the substituents and methanol molecules.

\subsection{Crystal Conformations of $M \alpha N P$ Salts}

The conformations of the M $\alpha \mathrm{NP}$ anions in salts 6-9 were similar to the major conformations of M $\alpha$ NP esters (Table 2) [2,6]: (1) The carboxylate oxygen atom O1 was synperiplanar to the methoxy oxygen atom O3; (2) The methoxy carbon atom $\mathrm{C} 4$ was antiperiplanar to the carboxylate carbon atom C1; (3) The methyl carbon atom C3 was in the naphthyl plane. The 1-arylethylammonium cations of salts 6-9 also exhibited the conformations similar to those of PEA cations [20]; that is, the benzylic hydrogen atom $\mathrm{H} 15$ was almost in the phenyl plane. 
Table 2. Conformational parameters of salts 6-9.

\begin{tabular}{cccccc}
\hline Salt & Substituent & O1-C1-C2-O3 $\left(^{\circ}\right)$ & C4-O3-C2-C1 $\left(^{\circ}\right)$ & C3-C2-C5-C6 $\left(^{\circ}\right)$ & N1-C15-C17-C22 $\left(^{\circ}\right)$ \\
\hline $\mathbf{6}$ & $p-\mathrm{MeO}$ & $-26.4(3)$ & $-178.0(3)$ & $-5.3(4)$ & $49.0(4)$ \\
$\mathbf{7}$ & $p-\mathrm{F}$ & $-28.9(2)$ & $179.9(1)$ & $2.7(2)$ & $53.0(2)$ \\
$\mathbf{8}$ & $p-\mathrm{Cl}$ & $-26.9(3)$ & $-179.3(2)$ & $-5.9(4)$ & $48.8(4)$ \\
$\mathbf{9}$ & $m-\mathrm{Cl}$ & $-26.5(2)$ & $178.4(1)$ & $0.2(2)$ & $47.1(2)$ \\
\hline
\end{tabular}

The 3-chlorophenyl group of salt 9 was fixed in the solid state; thus, the conformation of the (R)-1-(3-chlorophenyl)ethylammonium cation was elucidated using the concept of planar chirality [14] (Figure 4A): (1) The nitrogen atom N1, selected as the pilot atom, was not in the phenyl plane itself but was attached to the benzylic carbon atom at the end of the phenyl plane; (2) Considering the Cahn-Ingold-Prelog rules on the priority of ortho-carbon atoms, the three adjacent, in-plane carbon atoms 1-3 were selected; (3) Viewed from the pilot atom N1, the carbon atoms 1-3 were positioned in an anticlockwise direction in crystalline salt 9 . Therefore, the planar chirality of the (R)-1-(3-chlorophenyl)ethylammonium cation was assigned to ${ }^{\mathrm{pl}} S$.

(A) Salt 9

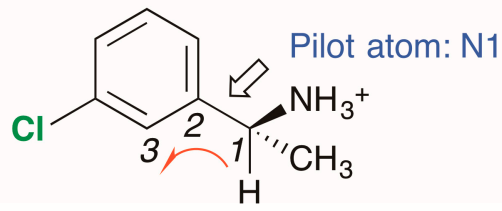

Planar chirality: pls

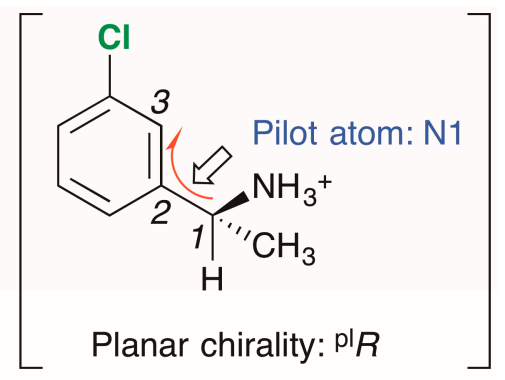

Planar chirality: $\left.{ }^{\mathrm{pl} R}\right]$

\section{(B) Salt 6}

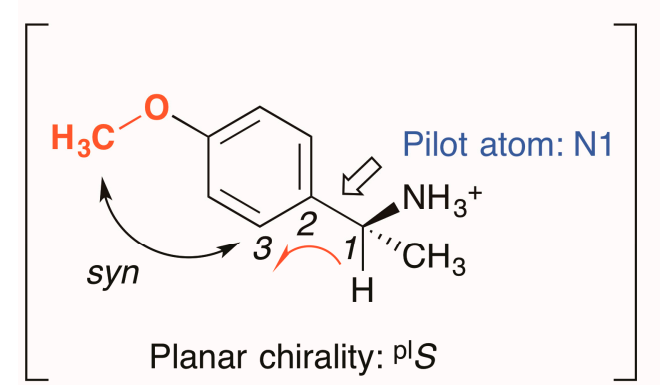

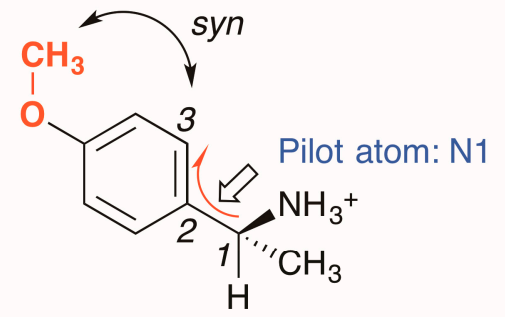

Planar chirality: pl $R$

Figure 4. Planar chirality of (R)-1-arylethylammonium cations in crystalline (A) salt 9 and (B) salt 6. The symbols "pl $S$ " and "pl $R$ " represent left- and right-handed planar chirality, respectively. In salt 6, higher priority was given to the ortho-carbon atom that is syn to the methoxy group.

In salt 6, the methoxy group of the (R)-1-(4-methoxyphenyl)ethylammonium cation is in the phenyl plane [15] (Figure 3). Considering the orientation of the methoxy group, the ortho-carbon atom 3 was selected so as to be syn to the methoxy group (Figure $4 \mathrm{~B}$ ). The three adjacent carbon atoms 1-3 were positioned in a clockwise direction in crystalline salt 6; thus, the planar chirality of the (R)-1-(4-methoxyphenyl)ethylammonium cation was assigned as ${ }^{\mathrm{pl}} R$. It should be noted that the planar chirality of the (R)-1-arylethylammonium cations in salts $\mathbf{6}$ and $\mathbf{9}$ is not genuine due to the unrestricted rotation of the $\mathrm{C} 15-\mathrm{C} 17$ bonds.

\subsection{Three-Step Hierarchical Assembly}

The molecular packing of salts $\mathbf{6 - 9}$ was interpreted as a three-step hierarchical assembly $[12,13]$ (Figure 5): 
1. Close ion-pairs joined with salt bridges to form $2_{1}$ columns.

2. The $2_{1}$ columns formed a sheet structure via homo-aromatic $\mathrm{C}-\mathrm{H} \cdots \pi$ interactions between 1-naphthyl groups.

3. These sheet structures stacked to form the whole crystal.

The para-substituents of 1-arylethylammonium cations were positioned on the surface of sheet structures. Therefore, they were important in the latter stage of the hierarchical assembly. With salts possessing smaller para-substituents, such as salt $7(p-\mathrm{F})$ and salt $9(p-\mathrm{H})$, the sheet structures stacked in the same manner, yielding a space group $P 2_{1}$. With larger para-substituents, such as those of salt 6 ( $p$-OMe) and salt $8(p-\mathrm{Cl})$, the sheet structures stacked in an offset manner, yielding a space group $C 2$. In addition, the space between columns formed in salts possessing the larger substituents, that is, salts 6, 8, and 9, were filled with methanol molecules [19].

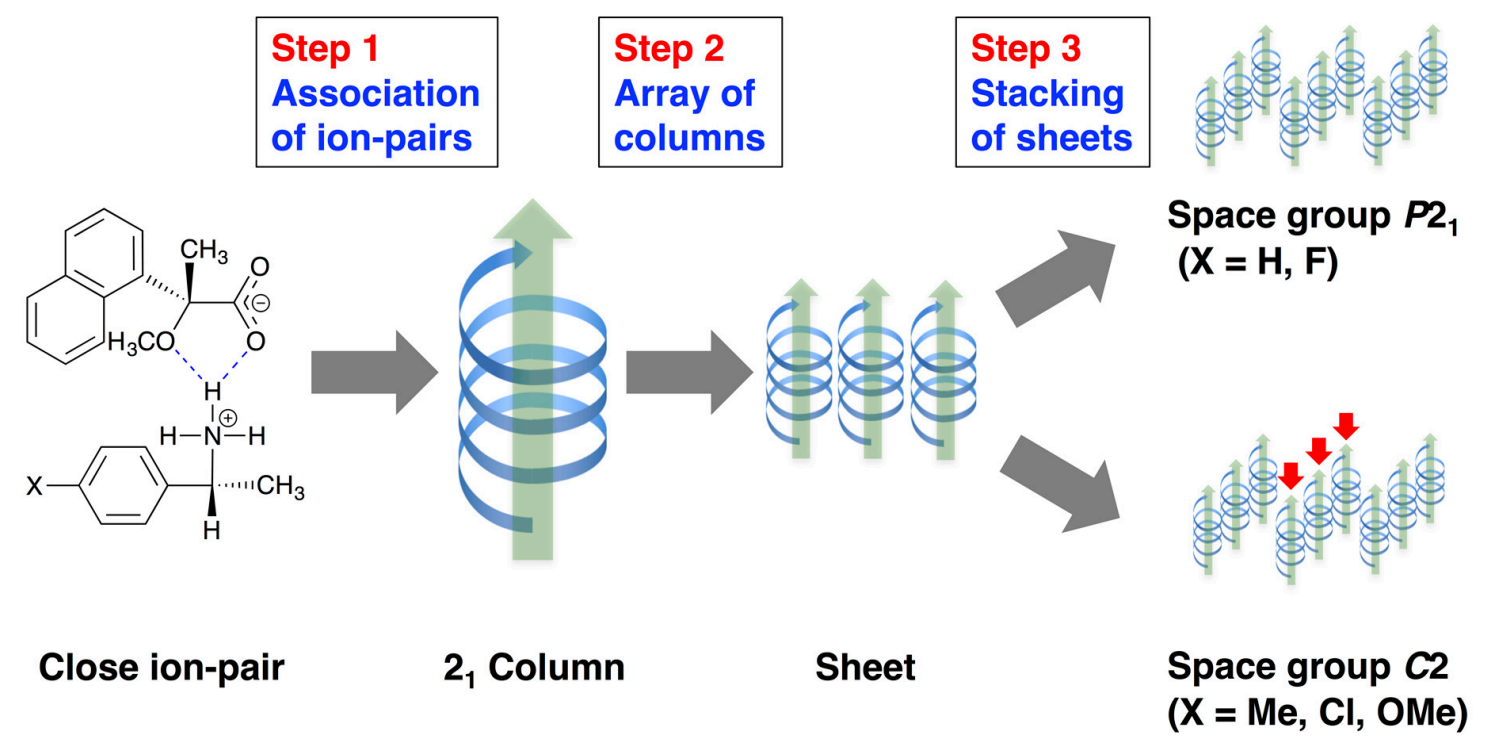

Figure 5. Three-step hierarchical assemblies of $\mathrm{M} \alpha \mathrm{NP}$ salts.

\subsection{Associations of Close Ion-Pairs}

The methoxy-group-assisted salt bridge and the aromatic $\mathrm{C}-\mathrm{H} \cdots \pi$ interactions joined the close ion-pairs of salts 6-9 as supramolecular synthons (Figures 2A and 3) [6]. Table 3 and Figure 6 show the geometrical parameters of salt bridges in close ion-pairs of salts $\mathbf{6 - 9}$.

Table 3. Geometrical parameters of methoxy-group-assisted salt bridges and other salt bridges in salts 6-9.

\begin{tabular}{|c|c|c|c|c|c|c|c|c|c|}
\hline Salt & Substituent & $d^{1}(\AA)^{1}$ & $\theta^{1}\left({ }^{\circ}\right)^{2}$ & $d^{2}(\AA)^{1}$ & $\theta^{2}\left({ }^{\circ}\right)^{2}$ & $d^{3}(\AA)^{1}$ & $\theta^{3}\left({ }^{\circ}\right)^{2}$ & $d^{4}(\AA)^{1}$ & $\theta^{4}\left({ }^{\circ}\right)^{2}$ \\
\hline 6 & $p-\mathrm{MeO}$ & 2.23 & 127 & 2.05 & 158 & 1.90 & 162 & 1.96 & 163 \\
\hline 7 & $p-\mathrm{F}$ & 2.33 & 125 & 2.02 & 161 & 1.89 & 166 & 1.90 & 163 \\
\hline 8 & $p-\mathrm{Cl}$ & 2.30 & 120 & 1.98 & 166 & 1.86 & 169 & 1.98 & 162 \\
\hline 9 & $m-\mathrm{Cl}$ & 2.25 & 128 & 2.06 & 158 & 1.89 & 161 & 1.98 & 161 \\
\hline
\end{tabular}




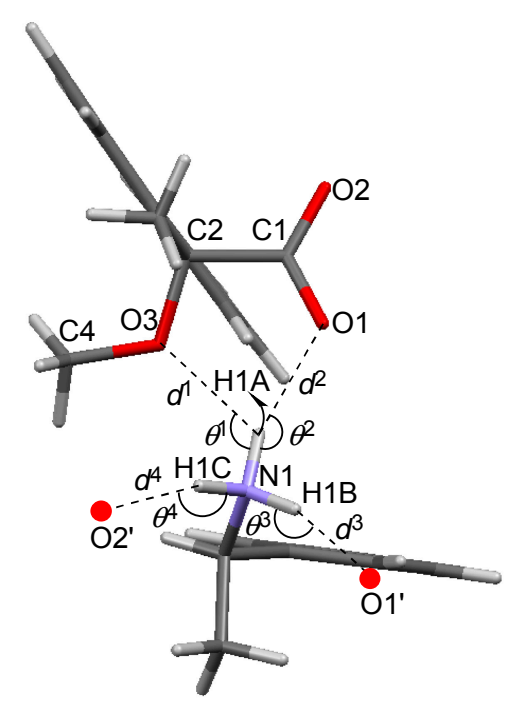

Figure 6. Geometrical parameters of methoxy-group-assisted salt bridges and other salt bridges in salts 6-9.

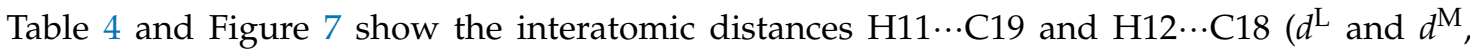
respectively) and the interatomic angles $\mathrm{C} 11-\mathrm{H} 11 \cdots \mathrm{C} 19$ and $\mathrm{C} 12-\mathrm{H} 12 \cdots \mathrm{C} 18$ in the close ion-pairs of salts 6-9. These data suggest the presence of aromatic $\mathrm{C}-\mathrm{H} \cdots \pi$ interactions [8]. It has been reported that the strength of these $\mathrm{C}-\mathrm{H} \cdots \pi$ interactions depends on the substituent in the phenyl group [9].

Table 4. Geometrical parameters of hetero-aromatic $\mathrm{C}-\mathrm{H} \cdots \pi$ interactions in the close ion-pairs of salts 6-9.

\begin{tabular}{|c|c|c|c|c|c|}
\hline Salt & Substituent & $d^{\mathrm{L}}(\AA)^{1}$ & $d^{\mathrm{M}}(\AA)^{1}$ & $\mathrm{C} 11-\mathrm{H} 11 \cdots \mathrm{C} 19\left(^{\circ}\right)$ & $\mathrm{C} 12-\mathrm{H} 12 \cdots \mathrm{C} 18\left(^{\circ}\right)$ \\
\hline 6 & $p-\mathrm{MeO}$ & 2.88 & 3.17 & 138 & 121 \\
\hline 7 & $p-\mathrm{F}$ & 2.98 & 3.15 & 141 & 126 \\
\hline 8 & $p-C l$ & 2.83 & 3.12 & 136 & 121 \\
\hline 9 & $m-\mathrm{Cl}$ & 3.01 & 3.29 & 136 & 123 \\
\hline
\end{tabular}

${ }^{1}$ Interatomic distances: $d^{\mathrm{L}}, \mathrm{H} 11 \cdots \mathrm{C} 19 ; d^{\mathrm{M}}, \mathrm{H} 12 \cdots \mathrm{C} 18$. H11 and $\mathrm{H} 12$ are offset slightly from the phenyl rings. Van der Waals radii: aromatic H, $1.00 \AA$ 解 half-thickness of the benzene ring, $1.77 \AA$.

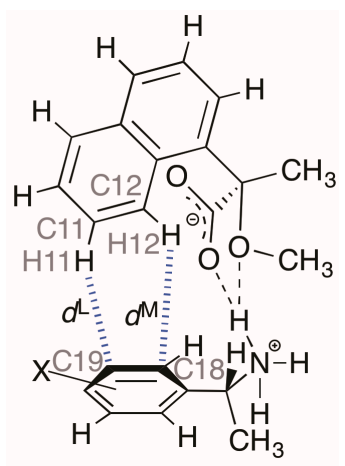

Figure 7. Geometrical parameters of hetero-aromatic $\mathrm{C}-\mathrm{H} \cdots \pi$ interactions in the close ion-pairs of salts 6-9.

Considering the virtual chiral center of the carboxylate and methoxy groups of the $(R)-\mathrm{M} \alpha \mathrm{NP}$ anion and the phenyl and ammonium groups of the $(R)-1$-arylethylammonium cation, each of the supramolecular chirality in the close ion-pairs of salts 6-9 was assigned as ${ }^{\text {sup }} S$ (Figures 2B and 3). This class of organic salts prefers the ${ }^{\sup S}$ association over the ${ }^{\sup } R$ association [10]. 


\subsection{Molecular Packing of MaNP Salts (1): Arrays of Columns}

The close ion-pairs of salts $\mathbf{6}-\mathbf{9}$ form $2_{1}$ columns via salt bridges (Figures $8-11$ ) [6,11]. Salts 6-9 revealed a similar herringbone motif [7] to form sheet structures. Table 5 and Figure 12 show the geometrical parameters of the homo-aromatic $\mathrm{C}-\mathrm{H} \cdots \pi$ interactions between the naphthyl groups of $(R)-\mathrm{M} \alpha \mathrm{NP}$ anions in salts 6-9. Space-filling models revealed that para-substituents of the 1-arylethylammonium cations are positioned on the sheet structures (Figure S1).

For smaller para-substituents, that is, salts $4[6], 9(p-\mathrm{H})$ and $7(p-\mathrm{F})$, the sheet structures stacked in the same manner to yield a space group $P 2_{1}$ (Figure 5). For larger para-substituents, that is, salt 5 $(p-\mathrm{Me})[11]$; salt $\mathbf{6}(p-\mathrm{MeO})$, and salt $\mathbf{8}(p-\mathrm{Cl})$, the sheets stacked in an offset manner to yield a space group $C 2$. These results indicate that the para-substituents defined the space groups of salts 4-9. The following factors are deemed important for the stability of the diastereomeric salts [17]: (1) hydrogen bonding to form 21 columns; (2) van der Waals interactions between the columns; and (3) intra- and intercolumnar $\mathrm{C}-\mathrm{H} \cdots \pi$ interactions. As noted above, methanol molecules filled the space [19] between the columns in salts 6,8 , and 9 .

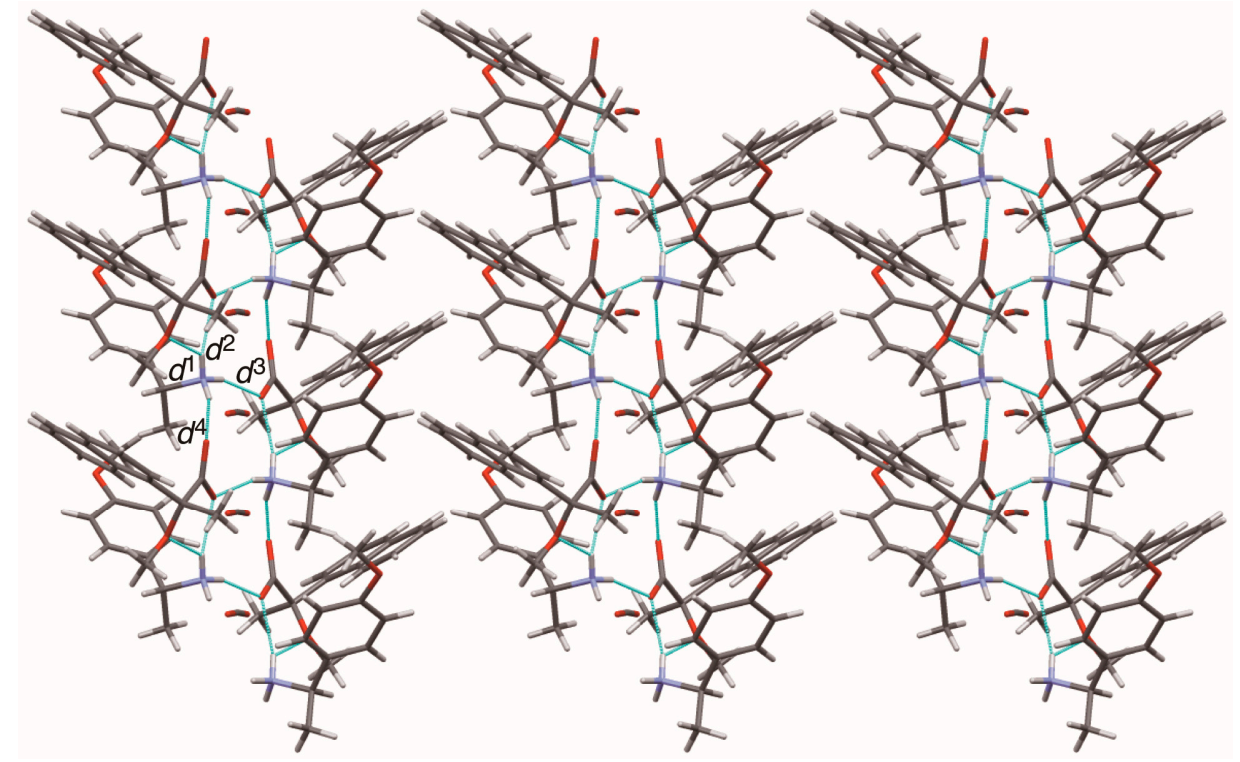

Figure 8. Sheet structure in crystalline salt 6 , consisting of $2_{1}$ columns. The pale-blue lines show salt bridges and hydrogen bonds. See Table 3 for the interatomic distances $d^{1}-d^{4}$.

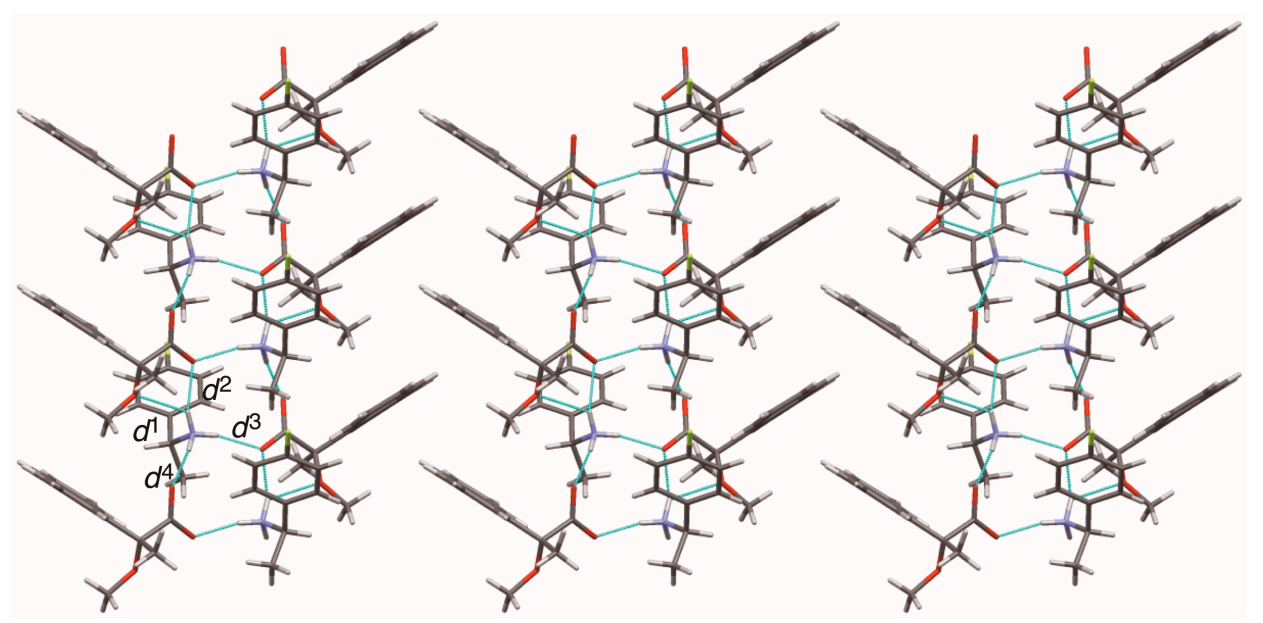

Figure 9. Sheet structure in crystalline salt 7 , consisting of $2_{1}$ columns. The pale-blue lines show salt bridges and hydrogen bonds. See Table 3 for the interatomic distances $d^{1}-d^{4}$. 


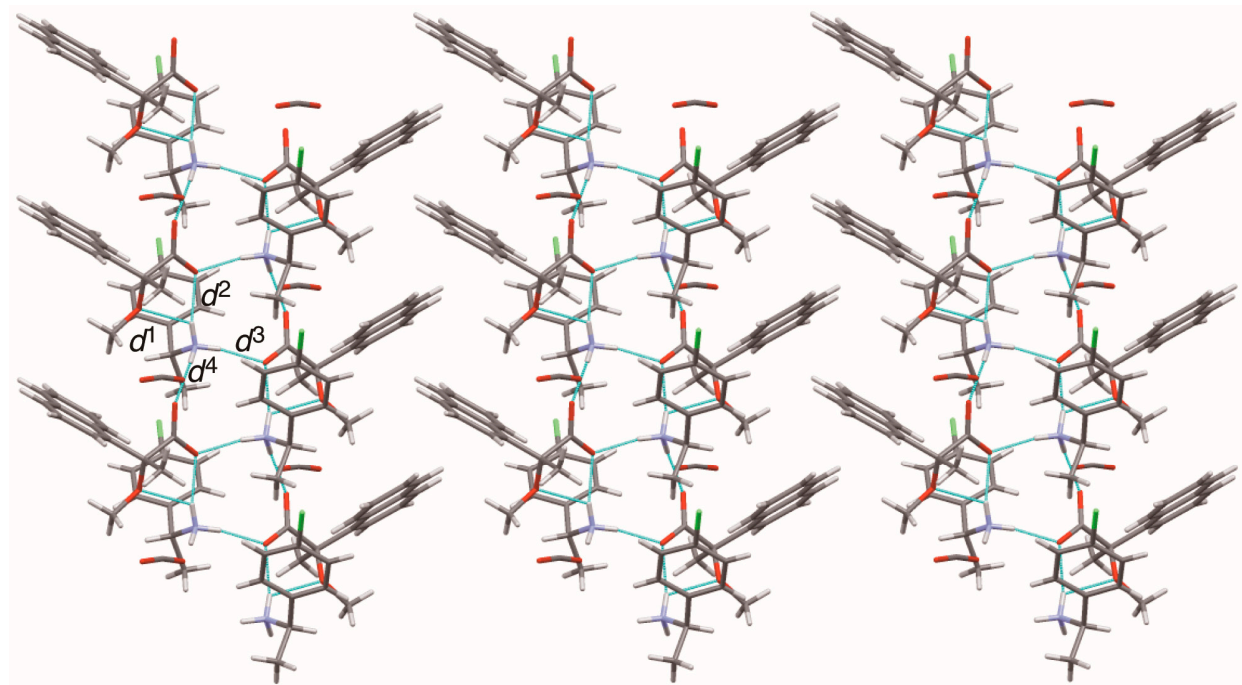

Figure 10. Sheet structure in crystalline salt 8 , consisting of $2{ }_{1}$ columns. The pale-blue lines show salt bridges and hydrogen bonds. See Table 3 for the interatomic distances $d^{1}-d^{4}$.

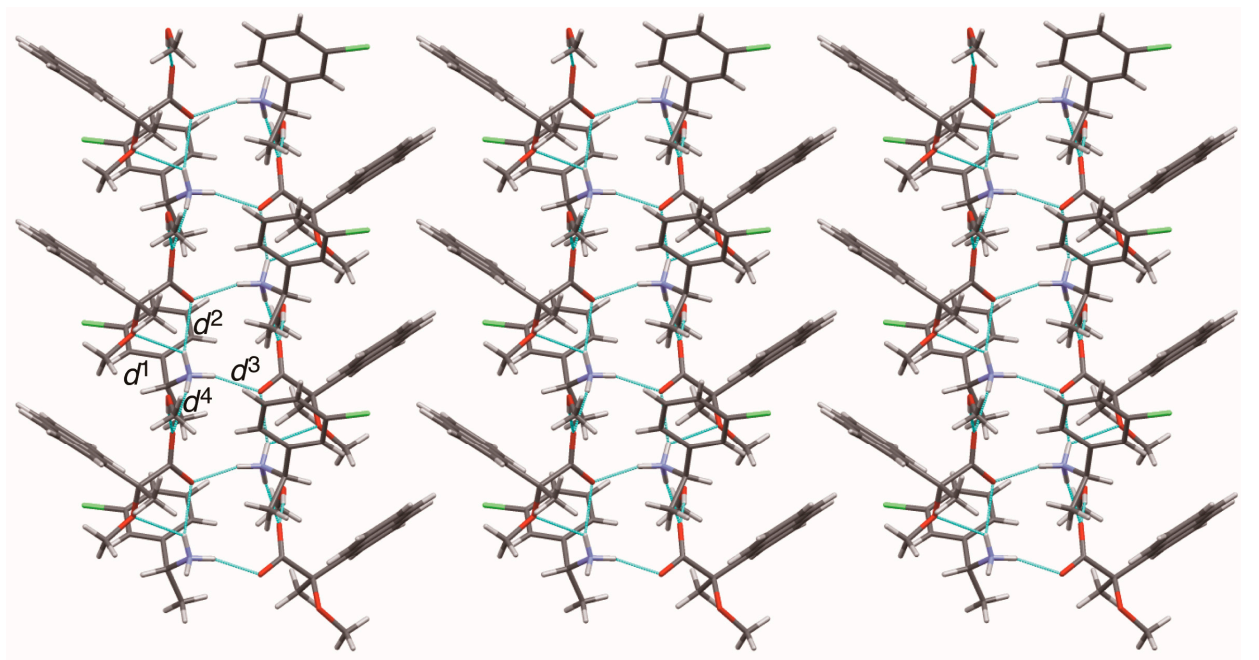

Figure 11. Sheet structure in crystalline salt 9, consisting of $2_{1}$ columns. The pale-blue lines show salt bridges and hydrogen bonds. See Table 3 for the interatomic distances $d^{1}-d^{4}$.

Table 5. Geometrical parameters of the homo-aromatic $\mathrm{C}-\mathrm{H} \cdots \pi$ interactions between the naphthyl groups in salts $6-9^{1}$.

\begin{tabular}{|c|c|c|c|c|c|}
\hline Salt & Substituent & $\mathrm{H} 9 \cdots \mathrm{Cg}^{X}(\AA)$ & $\mathrm{H} 10 \cdots \mathrm{Cg}^{\mathrm{Y}}(\AA)$ & $\mathrm{C} 9-\mathrm{H} 9 \cdots \mathrm{Cg}^{\mathrm{X}}\left({ }^{\circ}\right)$ & $\mathrm{C} 10-\mathrm{H} 10 \cdots \mathrm{Cg}^{\mathrm{Y}}\left({ }^{\circ}\right)$ \\
\hline 6 & $p-\mathrm{MeO}$ & 2.50 & 3.05 & 145 & 137 \\
\hline 7 & $p-\mathrm{F}$ & 2.62 & 3.41 & 155 & 127 \\
\hline 8 & $p-C l$ & 2.53 & 3.02 & 145 & 135 \\
\hline 9 & $m-\mathrm{Cl}$ & 2.66 & 3.36 & 155 & 126 \\
\hline
\end{tabular}

${ }^{1}$ Centroids of benzene rings: $\mathrm{Cg}^{\mathrm{X}}, \mathrm{C} 9-\mathrm{C} 14 ; \mathrm{Cg}^{\mathrm{Y}}$, C5-C6-C7-C8-C14-C-13. Van der Waals radii: aromatic H, $1.00 \AA$; half-thickness of the benzene ring, $1.77 \AA$. 


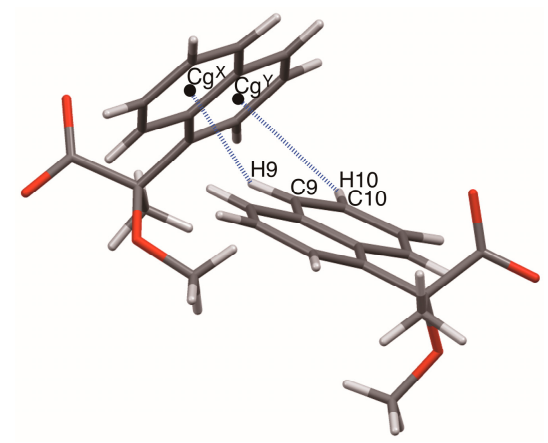

Figure 12. Geometrical parameters of the homo-aromatic $\mathrm{C}-\mathrm{H} \cdots \pi$ interactions between the naphthyl groups in salts 6-9. Centroids of benzene rings: $\mathrm{Cg}^{\mathrm{X}}, \mathrm{C} 9-\mathrm{C} 14 ; \mathrm{Cg}^{\mathrm{Y}}, \mathrm{C} 5-\mathrm{C} 6-\mathrm{C} 7-\mathrm{C} 8-\mathrm{C} 14-\mathrm{C}-13$.

\subsection{Molecular Packing of M $\alpha$ NP Salts (2): Stacking of Sheet Structures}

The interactions between sheet structures were examined in crystalline salts $\mathbf{7}$ and $\mathbf{9}$ (Figure 13 and Table 6). The sheet structures of salts 7 and 9 (Figures 9 and 11, respectively) stacked in a space group $P 2{ }_{1}$. The interactions between $p$-fluorophenyl groups in crystalline salt 7 were similar to those of phenyl groups in crystalline salt 4 [6]. There were no intermolecular contacts shorter than the sum of the van der Waals radii between the sheet structures of salt 7. The aromatic hydrogen atom H18 of the $p$-fluorophenyl group was relatively close to the neighboring fluorine atom F1'. The interatomic distance between $\mathrm{H} 18 \cdots \cdot \mathrm{F}^{\prime}$ ' was $2.61 \AA$ (the van der Waals radii: aromatic $\mathrm{H}, 1.00 \AA$; F, $1.47 \AA$ ) while the interatomic angle $\mathrm{C} 18-\mathrm{H} 18 \cdots \mathrm{F} 1^{\prime}$ was $118^{\circ}$. However, the $\mathrm{C}-\mathrm{H} \cdots \mathrm{F}$ interaction is reportedly very weak [21]. Despite large differences in physical and chemical properties, the substitution of a fluorine atom for a hydrogen atom only marginally affected the molecular packing.

A clear homo-aromatic $\mathrm{C}-\mathrm{H} \cdots \pi$ interaction was observed between the $m$-chlorophenyl groups of salt 9 (Figure 13). The interatomic distance between the aromatic hydrogen atom $\mathrm{H} 2 \mathrm{O}^{\prime}$ and the centroid of the neighboring phenyl ring $(\mathrm{Cg})$ was $2.72 \AA$ while the interatomic angle $\mathrm{C} 20^{\prime}-\mathrm{H} 20^{\prime}-\mathrm{Cg}$ was $170^{\circ}$. Kinbara et al. reported that the para-chlorine substituent of the 1-(4-chlorophenyl)ethylammonium cation increases the positive charge of the meta-hydrogen atoms, effectively stabilizing the $\mathrm{C}-\mathrm{H} \cdots \pi$ interaction [18]. In contrast, the chlorine atom of salt 9 did not show any short contacts (e.g., $\mathrm{Cl} \cdots \mathrm{Cl}$, $\mathrm{Cl} \cdots \mathrm{O}$, or $\mathrm{Cl} \cdots \pi$ interactions [22]). The same is true for the chlorine atom of salt 8 (see below).

\section{Space group $P 2_{1}$}
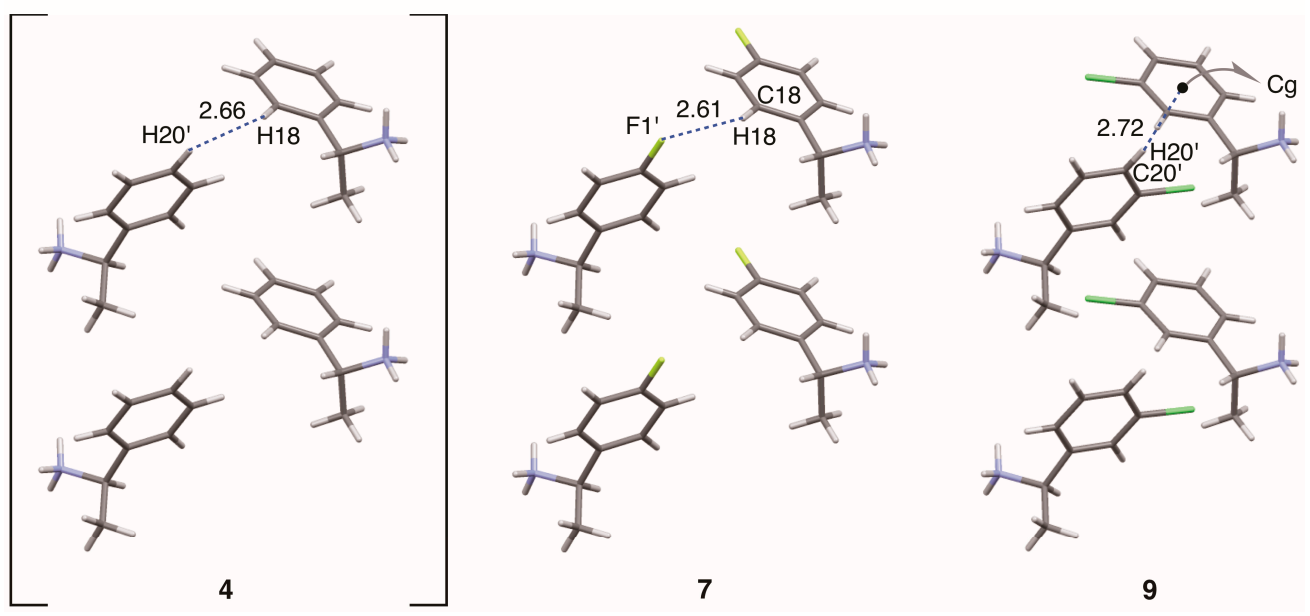

Figure 13. Molecular packing of salts 4 and 7 viewed along the $a$-axis, and salt 9 viewed along the $c$-axis. Numbers without units represent interatomic distances $(\AA)$. Cg: centroid of the phenyl ring (C17-C22). Van der Waals radii: aromatic H, $1.00 \AA$; F, $1.47 \AA$; half-thickness of the benzene ring, $1.77 \AA$. 
Table 6. Interatomic distances and angles between the sheet structures of salts 6-9.

\begin{tabular}{|c|c|c|c|c|c|}
\hline Salt & Substituent & Interatomic Distance & $(\AA ̊)$ & Interatomic Angle & $\left(^{\circ}\right)$ \\
\hline \multirow[t]{5}{*}{6} & $p-\mathrm{MeO}$ & $\mathrm{H} 7 \cdots \pi^{\prime} 1$ & 2.65 & & \\
\hline & & $\mathrm{H} 7 \cdots \mathrm{Cg}^{\prime 2}$ & 3.30 & $\mathrm{C} 7-\mathrm{H} 7 \cdots \mathrm{Cg}^{\prime}{ }^{1}$ & 174 \\
\hline & & $\mathrm{H} 23 \mathrm{~A}^{\prime} \cdots \mathrm{C} 7$ & 2.97 & & \\
\hline & & $\mathrm{O} 2 \cdots \mathrm{O} 5$ & 2.84 & & \\
\hline & & $\mathrm{H} 21^{\prime} \cdots \mathrm{O} 5$ & 2.48 & $\mathrm{C} 21^{\prime}-\mathrm{H} 21^{\prime} \cdots \mathrm{O} 5$ & 138 \\
\hline 7 & $p-\mathrm{F}$ & $\mathrm{H} 18 \cdots \mathrm{F} 1^{\prime}$ & 2.61 & $\mathrm{C} 18-\mathrm{H} 18 \cdots \mathrm{F} 1^{\prime}$ & 118 \\
\hline \multirow[t]{4}{*}{8} & $p-\mathrm{Cl}$ & $\mathrm{H} 7 \cdots \pi^{\prime}{ }^{1}$ & 2.69 & & \\
\hline & & $\mathrm{H} 7 \cdots \mathrm{Cg}^{\prime 2}$ & 3.09 & $\mathrm{C} 7-\mathrm{H} 7 \cdots \mathrm{Cg}^{\prime}{ }^{1}$ & 165 \\
\hline & & $\mathrm{O} 2 \cdots \mathrm{O} 4$ & 2.83 & & \\
\hline & & $\mathrm{H} 21^{\prime} \cdots \mathrm{O} 4$ & 2.42 & $\mathrm{C} 21^{\prime}-\mathrm{H} 21^{\prime} \cdots \mathrm{O} 4$ & 133 \\
\hline \multirow[t]{2}{*}{9} & $m-\mathrm{Cl}$ & $\mathrm{H} 20^{\prime} \cdots \mathrm{Cg}^{2}$ & 2.72 & $\mathrm{C} 20^{\prime}-\mathrm{H} 20^{\prime} \cdots \mathrm{Cg}$ & 170 \\
\hline & & $\mathrm{H} 20^{\prime} \cdots \pi^{1}$ & 2.67 & & \\
\hline
\end{tabular}

${ }^{1}$ The phenyl plane is defined by carbon atoms C17-C18-C19. ${ }^{2} \mathrm{Cg}$ : centroid of the phenyl ring (C17-C22). Van der

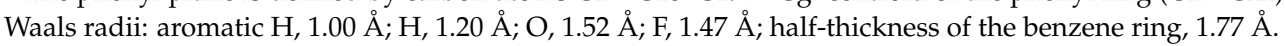

Finally, interactions between sheet structures were examined in crystalline salts $\mathbf{6}$ and $\mathbf{8}$. Figure 14 shows the molecular packing of salts 6 and 8 viewed along the $c$-axis. The sheet structures, shown in Figures 8 and 10, respectively, yielded a space group $C 2$ with hetero-aromatic $\mathrm{C}-\mathrm{H} \cdots \pi$ interactions between sheets. The aromatic hydrogen atom $\mathrm{H7}$ of the naphthyl group was positioned nearly on the edge of phenyl group in salts 6 and 8; the distances between $\mathrm{H7}$ and the neighboring phenyl plane were $2.65 \AA$ and $2.69 \AA$, respectively.

\section{Space group $C 2$}
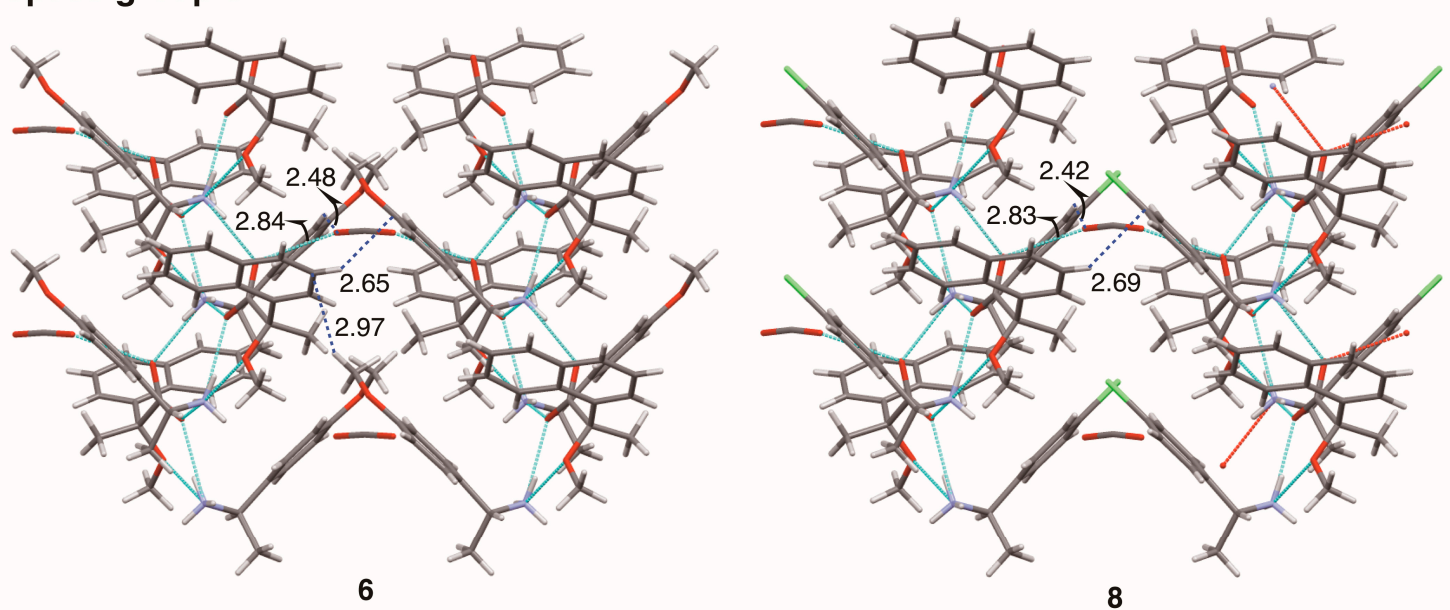

Figure 14. Molecular packing of salts 6 and 8 viewed along the $c$-axis. Numbers without units represent interatomic distances $(\AA)$. The pale-blue dotted lines indicate hydrogen bonds and salt bridges. Van der Waals radii: aromatic $\mathrm{H}, 1.00 \AA$;, $1.20 \AA$; O, $1.52 \AA$; half-thickness of the benzene ring, $1.77 \AA$.

In salt 6, the $p$-methoxy group was located in the phenyl plane [15], giving an extended herringbone motif; the interatomic distance between hydrogen atom $\mathrm{H}_{23} 3 \mathrm{~A}^{\prime}$ and aromatic carbon atom C7 was $2.97 \AA$. The chlorine atom of salt 8 had no short contacts with neighboring molecules. Methanol molecules filled the space between sheet structures in salts $\mathbf{6}$ and $\mathbf{8}$ (Figure 14). The oxygen atom of methanol molecule formed an $\mathrm{O}-\mathrm{H} \cdots \mathrm{O}$ hydrogen bond and a $\mathrm{C}-\mathrm{H} \cdots \mathrm{O}$ interaction. In salt 6 , 
the interatomic distances $\mathrm{O} 2 \cdots \mathrm{O} 5$ and $\mathrm{H} 21^{\prime} \cdots \mathrm{O} 5$ were $2.84 \AA$ and $2.48 \AA$, respectively. In salt 8, the interatomic distances $\mathrm{O} 2 \cdots \mathrm{O} 4$ and $\mathrm{H} 21^{\prime} \cdots \mathrm{O} 4$ were $2.83 \AA$ and $2.42 \AA$, respectively. In terms of crystal engineering, the $p$-methoxy group of salt $\mathbf{6}$ was isosteric with the $p$-chloro group of salt 8.

\section{Conclusions}

This study clarified the crystal structures of M $\alpha \mathrm{NP}$ salts 6-9 prepared from (R)-1 and (R)-1-arylethylamines. Using the concepts of supramolecular chirality, the solid-state associations of close ion-pairs were elucidated as $\sup S$ in all salts. In addition, the solid-state planar chirality of the (R)-1-(4-methoxyphenyl)ethylammonium cation of salt 6 and the (R)-1-(3-chlorophenyl)ethylammonium cation of salt 9 were assigned as ${ }^{\mathrm{pl}} R$ and ${ }^{\mathrm{pl}} S$, respectively. It should be noted that these are not genuine planar chirality due to unrestricted rotations. The crystal structures of $\mathrm{M} \alpha \mathrm{NP}$ salts 6-9 were interpreted as three-step hierarchical assemblies. Para-substituents of phenyl groups were positioned on sheet structures consisting of $2_{1}$ columns and thereby affected the sheet stacking. Smaller para-substituents, that is, salt $7(p-\mathrm{F})$ and salt $9(p-\mathrm{H})$, and larger para-substituents, that is, salt $6(p-\mathrm{OMe})$ and salt $8(p-\mathrm{Cl})$, yielded space groups $P 2_{1}$ and $C 2$, respectively. For $\mathrm{M} \alpha \mathrm{NP}$ salts, $p-\mathrm{H}$ and $p$-OMe groups were isosteric with $p-\mathrm{F}$ and $p$ - $\mathrm{Cl}$ groups, respectively. The 3-chlorophenyl groups of salt 9 exhibited homo-aromatic $\mathrm{C}-\mathrm{H} \cdots \pi$ interactions. For $(R)$-1-arylethylamines with larger substituents, methanol molecules filled the space in the crystal lattice. These results provide information on supramolecular chemistry for the design and preparation of single-enantiomer biofunctional molecules.

\section{Materials and Methods}

\subsection{X-ray Crystallography}

The single crystals (salt 6, $0.300 \times 0.100 \times 0.060 \mathrm{~mm}$; salt 7, $0.200 \times 0.200 \times 0.200 \mathrm{~mm}$; salt 8 , $0.550 \times 0.150 \times 0.100 \mathrm{~mm}$; salt $9,0.600 \times 0.600 \times 0.500 \mathrm{~mm}$ ) were covered with paraffin oil and mounted on a glass fiber, respectively. All measurements were made on a Rigaku Mercury70 diffractometer using graphite monochromated $\mathrm{Mo}-\mathrm{K} \alpha$ radiation, operating at $50 \mathrm{kV} / 40 \mathrm{~mA}$. Data were processed on a PC using CrystalClear Software (Rigaku, Tokyo, Japan). Structures were solved using direct methods and refined by full-matrix least-squares methods on $F_{2}$ (SHELXL-97). CCDC 1442523 (salt 6), CCDC 1442524 (salt 7), CCDC 1442525 (salt 8), and CCDC 1442526 (salt 9) contain the supplementary crystallographic data for this study, which can be obtained from The Cambridge Crystallographic Data Centre via www.ccdc.cam.ac.uk. Each crystal was dried in vacuo overnight at $80^{\circ} \mathrm{C}$ prior to elemental analysis.

\subsection{Preparation of Salt 6}

A mixture of $(R)-1(29.2 \mathrm{mg}, 127 \mu \mathrm{mol})$ and $(R)$-1-(4-methoxyphenyl)ethylamine (21.7 mg, 144 $\mu \mathrm{mol})$ was dissolved in $\mathrm{CHCl}_{3}$ and $\mathrm{MeOH}(0.5 \mathrm{~mL}$ and $1.5 \mathrm{~mL}$, respectively). The solution was warmed in a water bath at $45^{\circ} \mathrm{C}$ and concentrated to ca. $1 \mathrm{~mL}$ in vacuo. Then, the solution was allowed to stand at RT for 5 days to give colorless crystals of salt 6 (MeOH solvate; $13.7 \mathrm{mg}, 34 \mu \mathrm{mol}$ ) in $27 \%$ yield.

(R)-1-(4-Methoxyphenyl)ethylammonium (R)-2-methoxy-2-(1-naphthyl)propanoate (6). Elemental analysis calculated (\%) for $\mathrm{C}_{23.5} \mathrm{H}_{29} \mathrm{NO}_{4.5}(6 \cdot 0.5 \mathrm{MeOH}): \mathrm{C} 71.01, \mathrm{H} 7.35, \mathrm{~N} 3.52$; found: C 71.21, $\mathrm{H}$ 7.37, N 3.51 .

\subsection{Preparation of Salt 7}

A mixture of $(R)-\mathbf{1}(31.0 \mathrm{mg}, 135 \mu \mathrm{mol})$ and $(R)-1$-(4-fluorophenyl)ethylamine $(18.7 \mathrm{mg}, 134 \mu \mathrm{mol})$ was dissolved in $\mathrm{CHCl}_{3}$ and $\mathrm{MeOH}(2 \mathrm{~mL}$ and $1 \mathrm{~mL}$, respectively). Then, the solution was allowed to stand at RT for three days to give colorless crystals of salt 7 (32.6 mg, $88 \mu \mathrm{mol})$ in $66 \%$ yield.

(R)-1-(4-Fluorophenyl)ethylammonium (R)-2-methoxy-2-(1-naphthyl)propanoate (7). Elemental analysis calculated (\%) for $\mathrm{C}_{22} \mathrm{H}_{24} \mathrm{FNO}_{3}$ : C 71.53, $\mathrm{H}$ 6.55, N 3.79; found: C 71.52, H 6.22, N 3.72. 


\subsection{Preparation of Salt 8}

A mixture of $(R)-\mathbf{1}(31.5 \mathrm{mg}, 137 \mu \mathrm{mol})$ and $(R)-1$-(4-chlorophenyl)ethylamine (32.7 mg, $210 \mu \mathrm{mol})$ was dissolved in $\mathrm{CHCl}_{3}$ and $\mathrm{MeOH}(0.5 \mathrm{~mL}$ and $1.5 \mathrm{~mL}$, respectively). The solution was warmed in a water bath at $45^{\circ} \mathrm{C}$ and allowed to stand at RT for two days to give crude crystals of salt 8 . Recrystallization from $\mathrm{CHCl}_{3} / \mathrm{MeOH}(1 \mathrm{~mL}$ and $0.5 \mathrm{~mL}$, respectively) gave colorless crystals of salt 8 (MeOH solvate; $18.3 \mathrm{mg}, 46 \mu \mathrm{mol}$ ) with a total yield of $33 \%$.

(R)-1-(4-Chlorophenyl)ethylammonium $(R)$-2-methoxy-2-(1-naphthyl)propanoate (8). Elemental analysis calculated (\%) for $\mathrm{C}_{22.5} \mathrm{H}_{26} \mathrm{ClNO}_{3.5}(8 \cdot 0.5 \mathrm{MeOH}): \mathrm{C} 67.24, \mathrm{H} 6.52, \mathrm{~N}$ 3.49; found: C 67.55, H 6.28, N 3.53 .

\subsection{Preparation of Salt 9}

A mixture of $(R)-\mathbf{1}(29.9 \mathrm{mg}, 130 \mu \mathrm{mol})$ and $(R)-1$-(3-chlorophenyl)ethylamine (25.9 mg, $166 \mu \mathrm{mol})$ was dissolved in $\mathrm{CHCl}_{3}$ and $\mathrm{MeOH}(1 \mathrm{~mL}$ and $2 \mathrm{~mL}$, respectively). The solution was warmed in a water bath at $47^{\circ} \mathrm{C}$ and allowed to stand at RT for 10 days to give colorless crystals of salt $9(\mathrm{MeOH}$ solvate; $33.1 \mathrm{mg}$, $79 \mu \mathrm{mol})$ in $61 \%$ yield.

(R)-1-(3-Chlorophenyl)ethylammonium (R)-2-methoxy-2-(1-naphthyl)propanoate (9). Elemental analysis calculated (\%) for $\mathrm{C}_{22} \mathrm{H}_{24} \mathrm{ClNO}_{3}$ : C 68.48, $\mathrm{H}$ 6.27, N 3.63; found: C 68.50, H 6.24, N 3.56.

Supplementary Materials: The following is available online at www.mdpi.com/2073-4352/7/9/263/s1, Figure S1: Top and side views of sheet structures in salts 6-9 shown in space-filling models.

Author Contributions: Akio Ichikawa designed and performed the experiments; Yuji Mikata obtained and analyzed the data of X-ray crystallography; Akio Ichikawa, Hiroshi Ono, and Yuji Mikata discussed the results.

Conflicts of Interest: The authors declare no conflict of interest.

\section{References}

1. Mori, K. Bioactive natural products and chirality. Chirality 2011, 23, 449-462. [CrossRef] [PubMed]

2. Harada, N. Determination of absolute configurations by $\mathrm{X}$-ray crystallography and ${ }^{1} \mathrm{H}$ NMR anisotropy. Chirality 2008, 20, 691-723. [CrossRef] [PubMed]

3. Goto, J.; Hasegawa, M.; Nakamura, S.; Shimada, K.; Nambara, T. New derivatization reagents for the resolution of amino acid enantiomers by high-performance liquid chromatography. J. Chromatogr. 1978, 152, 413-419. [CrossRef]

4. Ichikawa, A.; Hiradate, S.; Sugio, A.; Kuwahara, S.; Watanabe, M.; Harada, N. Absolute configuration of 2-hydroxy-2-(1-naphthyl)propionic acid as determined by the ${ }^{1} \mathrm{H}$ NMR anisotropy method. Tetrahedron Asymmetry 1999, 10, 4075-4078. [CrossRef]

5. Ohtani, I.; Kusumi, T.; Kashman, Y.; Kakisawa, H. High-field FT NMR application of Mosher's method. The absolute congifurations of marine terpenoids. J. Am. Chem. Soc. 1991, 113, 4092-4096. [CrossRef]

6. Ichikawa, A.; Ono, H.; Echigo, T.; Mikata, Y. Crystal structures and chiral recognition of the diastereomeric salts prepared from 2-methoxy-2-(1-naphthyl)propanoic acid. CrystEngComm 2011, 13, 4536-4548. [CrossRef]

7. Desiraju, G.R. Hydrogen bridges in crystal engineering: Interactions without borders. Acc. Chem. Res. 2002, 35, 565-573. [CrossRef] [PubMed]

8. Kobayashi, K.; Hayashi, N. Solid State Organic Chemistry; Kagakudojin: Kyoto, Japan, 2009; pp. 31-33.

9. Nishio, M. New Edition: Introduction to Intermolecular Forces in Organic Chemistry; Kodansha Scientific: Tokyo, Japan, 2008; pp. 44-45.

10. Ichikawa, A.; Ono, H.; Mikata, Y. The crystal structure of the more-soluble Mosher's salt. Chem. Lett. 2017, 46, 550-553. [CrossRef]

11. Ichikawa, A.; Ono, H.; Mikata, Y. Naphthyl groups in chiral recognition: Structures of salts and esters of 2-methoxy-2-naphthylpropanoic acids. Chem. Asian J. 2012, 7, 2294-2304. [CrossRef] [PubMed]

12. Hisaki, I.; Sasaki, T.; Tohnai, N.; Miyata, M. Multipoint approximation method for handedness determination of two-fold helical assemblies and their bundles. J. Syn. Org. Chem. Jpn. 2012, 70, 908-917. [CrossRef]

13. Miyata, M.; Tohnai, N.; Hisaki, I. Crystalline host-guest assemblies of steroidal and related molecules: Diversity, hierarchy, and supramolecular chirality. Acc. Chem. Res. 2007, 40, 694-702. [CrossRef] [PubMed] 
14. Harada, K.; Hidaka, J. Stereochemistry, 2nd ed.; Dainippoon Tosho: Tokyo, Japan, 1994; pp. 129-130.

15. Müller, K.; Faeh, C.; Diederich, F. Fluorine in pharmaceuticals: Looking beyond intuition. Science 2007, 317, 1881-1886. [CrossRef] [PubMed]

16. Hernandes, M.Z.; Cavalcanti, S.M.T.; Moreira, D.R.M.; Filgueira de Azevedo, W., Jr.; Leite, A.C.L. Halogen atoms in the modern medicinal chemistry: Hints for the drug design. Curr. Drug Targets 2010, 11, 303-314. [CrossRef] [PubMed]

17. Saigo, K.; Sakai, K. Toward efficient optical resolution by diastereomeric salt formation. J. Synth. Org. Chem. Jpn. 2011, 69, 499-505. [CrossRef]

18. Kinbara, K.; Oishi, K.; Harada, Y.; Saigo, K. Effect of a substituent on an aromatic group in diastereomeric resolution. Tetrahedron 2000, 56, 6651-6655. [CrossRef]

19. Sakai, K. Industrial-scale optical resolution with the diastereomeric salt formation method-A novel resolution technology using molecular recognition mechanism. Chem. Chem. Ind. 2004, 57, 507-511.

20. Karamertzanis, P.G.; Price, S.L. Challenges of crystal structure prediction of diastereomeric salt pairs. J. Phys. Chem. B 2005, 109, 17134-17150. [CrossRef] [PubMed]

21. Reichenbächer, K.; Süss, H.I.; Hulliger, J. Fluorine in crystal engineering- "The little atom that could". Chem. Soc. Rev. 2005, 34, 22-30. [CrossRef] [PubMed]

22. Imai, Y.N.; Inoue, Y.; Nakanishi, I.; Kitaura, K. Cl- $\pi$ interactions in protein-ligand complexes. Protein Sci. 2008, 17, 1129-1137. [CrossRef] [PubMed]

(C) 2017 by the authors. Licensee MDPI, Basel, Switzerland. This article is an open access article distributed under the terms and conditions of the Creative Commons Attribution (CC BY) license (http:/ / creativecommons.org/licenses/by/4.0/). 